\title{
Devices Used for CPAP Delivery
}

\author{
Teresa A Volsko
}

\author{
Introduction \\ Types of Devices Used to Deliver CPAP \\ Oxygen-Conserving Valved CPAP Systems \\ Continuous-Flow CPAP Generators \\ Portable Demand-Flow CPAP Devices \\ Mechanical Ventilators \\ Device Selection for CPAP Delivery \\ Summary
}

\begin{abstract}
CPAP is a spontaneous mode of ventilation that maintains a constant airway pressure during the inspiratory and expiratory phases. This therapeutic modality is used across the continuum of care from pre-hospital treatment to intensive and acute care units to the home care environment to treat a host of acute and chronic clinical conditions. A variety of devices are currently available for the delivery of CPAP, including oxygen-conserving valved systems, continuous-flow generators, portable demand-flow devices, and mechanical ventilators. The devices used to administer CPAP vary in complexity, performance, monitoring capabilities, ability to provide humidification, and safety features. Regardless of the type of device or system used to deliver CPAP, a system that is unable to meet or exceed the patient's flow demands has the propensity to deliver pressure and oxygen concentrations that are lower than intended or set. If undetected, this can contribute to adverse patient outcomes. Considerations for device selection depend on the setting (eg, pre-hospital, acute care, critical care, home care), length of therapy (ie, short vs long-term), patient safety (eg, alarms, monitoring devices), and comfort. Understanding the science and clinical application of CPAP delivery systems can assist clinicians in a variety of care settings with selecting the type of device that best matches the clinical setting, and thus with optimizing therapeutic effectiveness by maximizing patient comfort, safety and stability of pressure, and $\mathrm{F}_{\mathrm{IO}}$ delivery. Key words: continuous positive airway pressure; threshold resistors. [Respir Care 2019;64(6):723-734. @ 2019 Daedalus Enterprises]
\end{abstract}

\section{Introduction}

CPAP is defined as a constant airway pressure maintained during the inspiratory and expiratory phases. ${ }^{1}$ This therapeutic modality is classified as a spontaneous mode

Ms Volsko is affiliated with the Nursing Administration, Akron Children's Hospital, Akron, Ohio.

The author has disclosed a relationship with Prospiria.

Ms Volsko presented a version of this paper at the 57th RESPIRATORY CARE Journal Conference, held June 14-15, 2018, in St Petersburg, Florida. of ventilation because inspiratory effort is not actively assisted. CPAP can be administered invasively through a tracheal tube or through a noninvasive interface. CPAP elevates intrathoracic and alveolar pressure, which improves the distribution of ventilation by increasing functional residual capacity and promoting collateral ventila-

\footnotetext{
Correspondence: Teresa A Volsko MBA MHHS RRT CMTE FAARC, Nursing Administration Akron Children's Hospital, Akron, Ohio 44308. E-mail: tvolsko@akronchildrens.org.
}

DOI: $10.4187 /$ respcare. 06625 


\section{DEVICES FOR CPAP}

tion. ${ }^{2}$ When used noninvasively, this therapeutic modality also splints the airway open, preventing upper-airway collapse. $^{3}$

CPAP has been used along the continuum of care to treat acute and chronic pulmonary manifestations. The application of positive pressure to the airways decreases the work of breathing by reducing airway resistance and the inspiratory effort required to initiate a spontaneous breath in the presence of intrinsic PEEP. ${ }^{4}$ The literature also reports its beneficial effects on the cardiovascular system, which includes a reduction of both the cardiac preload and afterload by decreasing cardiac filling and left ventricular transmural pressure. ${ }^{5,6}$

During spontaneous breathing, the CPAP level will vary with changes in the breathing cycle, decreasing during inspiration and increasing during exhalation. The literature reports that changes in the set CPAP level of up to $2 \mathrm{~cm} \mathrm{H}_{2} \mathrm{O}$ are associated with a normal work of breathing. ${ }^{7}$ An effective CPAP delivery system should have the capability to deliver a flow of gas sufficient to meet the patient's inspiratory demands. Patients requiring CPAP therapy often present with high minute ventilation due to tachypnea or higher-than-normal inspired tidal volumes. Systems that deliver a flow of at least $60 \mathrm{~L} / \mathrm{min}$ will, under most circumstances, meet an adult patient's inspiratory demand and minimize variations in the delivered CPAP level. ${ }^{8}$ It is equally important that the CPAP system have a mechanism to lessen the propensity for increasing the expiratory work of breathing as the patient exhales against a high fixed flow of gas. There are many different types of commercially available devices that can be used to deliver CPAP across the continuum of care. This paper will describe the different devices and systems used to deliver CPAP to adults who require this form of therapy in the pre-hospital, intensive care, and acute care settings.

\section{Types of Devices Used to Deliver CPAP}

A variety of devices can be used to deliver CPAP, including oxygen-conserving valved systems, continuousflow generators, portable demand-flow devices, and mechanical ventilators. Oxygen-conserving valved systems are not dependent on a power source to function, but they have the ability to deliver supplemental oxygen when needed. Pneumatically and electrically powered devices may also be used to deliver continuous positive pressure above atmospheric to the airways. Considerations for device selection depend on the setting (eg, pre-hospital, acute care, critical care, home care), length of therapy (ie, short vs long term), patient safety (eg, alarms, monitoring devices), and comfort. This paper will focus on devices used in the pre-hospital, interfacility transport, and critical care settings.

\section{Oxygen-Conserving Valved CPAP Systems}

Threshold resistors, when incorporated into a pressurized circuit, provide a fixed resistance to the patient's inspiratory and expiratory flow throughout the respiratory cycle. These devices may incorporate a weighted-ball or spring-loaded mechanism to maintain a constant airway pressure throughout the respiratory cycle.

Weighted-ball threshold resistors incorporate a ball of a known size and density to restrict gas flow through a calibrated orifice until a threshold back pressure is achieved. As the ball floats off the orifice inside the resistor, the system is opened to pressure. Weighted-ball threshold resistors are gravity-dependent and require the valve to remain in an upright position to deliver a constant pressure. Changes in the position of the device will cause variations in CPAP levels. When these devices are used with a closed CPAP system, patient positioning may be limited to ensure the valve remains upright. Commercially available threshold resistors are individually calibrated and require an exchange of or change to the resistor incorporated in the closed CPAP system to alter the set pressure delivered to the patient.

Spring-loaded valves are not dependent on gravity. The amount of positive pressure maintained is proportional to the tension on the spring. Changes in CPAP levels can be made by adjusting the amount of tension on the spring. Patient movement or position are not restricted when this type of threshold resistor is used to deliver CPAP.

Threshold resistors do not require the patient's flow to remain constant to create CPAP, and impose minimal resistance above opening pressure to achieve and maintain the desired pressure delivery. ${ }^{9}$ Changes in flow due to variations in the patient's breathing pattern (eg, sigh breaths or coughing) will have minimal effect on the level of CPAP delivered to the patient. Commercially available products designed for use with adults typically deliver CPAP at levels of 5-20 $\mathrm{cm} \mathrm{H}_{2} \mathrm{O}$. The literature reports variations in CPAP level with a threshold resistance value $<1.0 \mathrm{~cm} \mathrm{H}_{2} \mathrm{O}$ during quiet breathing, at a tidal volume of $700 \mathrm{~mL}$ and a maximum inspiratory flow of $1.35 \mathrm{~L} / \mathrm{s}^{10}$

There are several commercially available, single-use CPAP systems that incorporate air-entrainment valves to provide sufficient flow through a valved CPAP system. This type of system also allows for the delivery of supplemental oxygen in conjunction with flows adequate to maintain the desired level of CPAP. Figure 1 provides an example of CPAP systems that incorporate a weightedball threshold resistor and a spring-loaded threshold resistor. These types of devices are well suited for the prehospital and transport environment because a power source is not needed for the device to function, low to high concentrations of oxygen can be delivered by a portable ox- 


\section{DEVICES FOR CPAP}
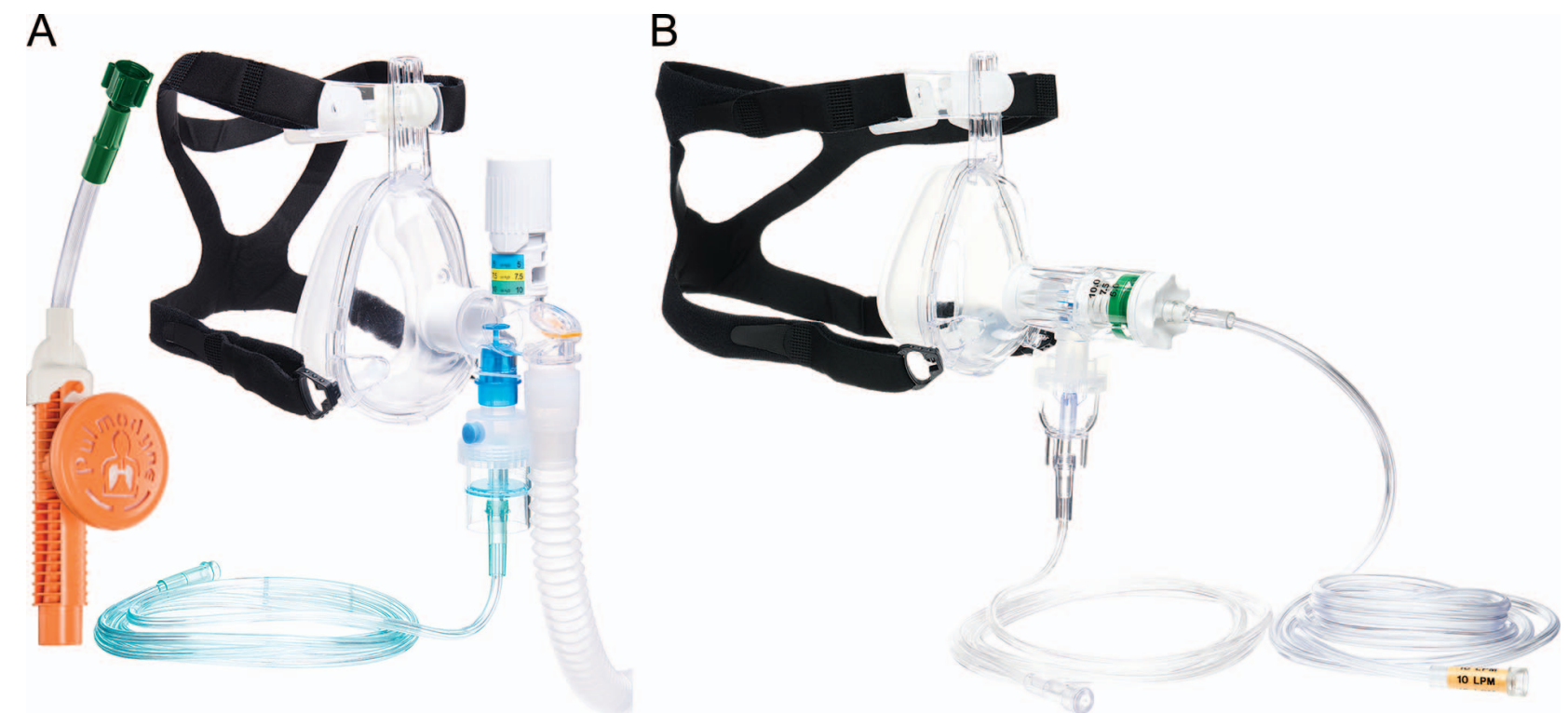

Fig. 1. Commercially available systems that incorporate different types of threshold resistor to generate CPAP. A: $\mathrm{O}_{2}-\mathrm{Max}(\mathrm{Pulmodyme}$, Indianapolis, IN) uses a weighted-ball threshold resistor. The threshold resistor, positioned vertically and attached to the CPAP mask, needs to remain in the vertical position to function properly. B: GO-PAP (Pulmodyme) uses a spring-loaded valve. This type of threshold resistor is not position-dependent and can be seen attached to the CPAP mask. Courtesy Pulmodyne.

Table 1. Example of CPAP Pressures and Delivered $\mathrm{F}_{\mathrm{IO}_{2}}{ }^{*}$

\begin{tabular}{lcc}
\hline \hline $\begin{array}{c}\text { Set Flow, } \\
\text { L/min }\end{array}$ & $\begin{array}{c}\text { Delivered CPAP Pressure, } \\
\mathrm{cm} \mathrm{H}_{2} \mathrm{O}\end{array}$ & $\mathrm{F}_{\mathrm{IO}_{2}}$ \\
\hline 8 & 5 & 0.54 \\
10 & 8 & 0.59 \\
12 & 10 & 0.62 \\
15 & 15 & 0.67 \\
20 & 20 & 0.73 \\
25 & 25 & 0.77
\end{tabular}

* Data from the O-Two single-use CPAP device (O-Two, Brampton, Ontario, Canada).

ygen cylinder, and flow meter and patient position is not limited when a spring-loaded resistor is used.

Flow-resistant devices produce CPAP that varies with the amount of gas passing through the orifice of the valve. ${ }^{11}$ During a normal respiratory cycle, flow will be lower during inspiration and higher during exhalation. Pressure is affected by the flow of gas through the valve and the size of the orifice. Table 1 provides an example of the range of pressure and $\mathrm{F}_{\mathrm{IO}_{2}}$ delivered by a commercially available flow-dependent resistor device and demonstrates the direct proportional effect that flow has on CPAP delivery. Pressure delivered to the airway will decrease as flow decreases, and it will increase as flow increases through the device. Some devices allow pressure to be adjusted by altering the size of the valve's orifice. When these devices are used, the pressure delivered to the patient is inversely proportional to the size of the orifice. ${ }^{11}$
Therefore, as the size of the orifice decreases, resistance to flow increases and the amount of pressure delivered to the airway increases. In a simulated lung model, the high gasflow resistance through the valve was found to impose a considerable amount of work throughout the respiratory cycle when the continuous flow exceeded the peak inspiratory flow demand. ${ }^{11}$ Similar to devices that use a threshold resistor, these devices are lightweight and can be attached to a portable oxygen cylinder and flow meter for use. There are advantages and challenges with the use of threshold and flow resistors to deliver CPAP in the ICU, as well as in the pre-hospital and transport environments. Table 2 compares and contrasts gas consumption, pressure monitoring, and alarm features of weighted-ball and springloaded threshold resistors with flow resistors used for CPAP delivery. The predominant use of these types of devices is in the emergency setting (eg, pre-hospital, transport, and the emergency department). Their ease of use and economical gas consumption make them well suited for the pre-hospital and transport environments. Lack of alarm and patient-monitoring capabilities limits their use in acute and intensive care settings.

\section{Continuous-Flow CPAP Generators}

Continuous-flow systems require a power source to generate flow. Some pneumatically powered systems require an air source and an oxygen source attached to a blender, while others incorporate an air-entrainment system to allow adjustments in $\mathrm{F}_{\mathrm{IO}_{2}}$ to occur. Continuous-flow CPAP 


\section{DEVICES FOR CPAP}

Table 2. Comparison of Valved CPAP Delivery Devices and Their Use Across the Continuum of Care

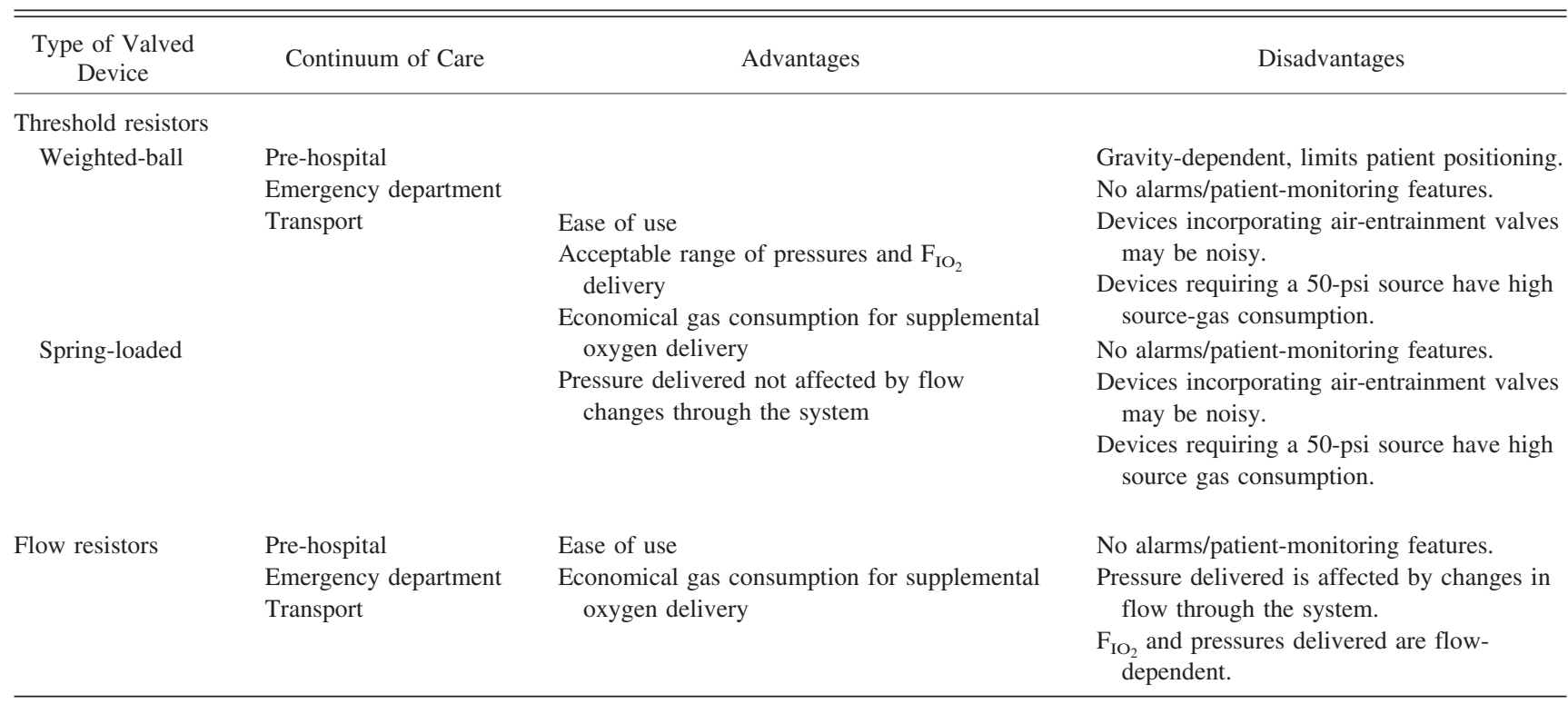

generators typically have dual-limb circuits and a mechanism to provide humidification and they incorporate a resistor on the expiratory end of the circuit to achieve and maintain the set level of constant distending pressure. However, to achieve and maintain a constant CPAP level, the system must deliver flows that at least meet the patient's inspiratory flow demands. Water-column threshold resistors are gravity-dependent CPAP generators. The amount of pressure delivered to the airways is dependent on the force exerted on a column of water. The depth of the expiratory tube in the water column and the amount of water in the column are used to determine the pressure delivered to the patient. ${ }^{12,13}$ Although this mode of CPAP delivery is not routinely used to deliver CPAP to adults, the literature reports favorable results in the treatment of respiratory distress and apnea in preterm infants. CPAP delivered in this manner has the added effect of air-flow oscillations, due to the bubbling of flow through the water column (this method is often referred to as bubble CPAP). Infants treated with bubble CPAP had fewer complications (eg, chronic lung disease), ${ }^{14}$ shorter hospital lengths of stay, ${ }^{15}$ and a lower cost of care, ${ }^{16}$ making this a viable option for the treatment of respiratory distress in newborn infants. These systems are simple and do not have alarms or a mechanism to verify the pressure delivered to the patient. Noise associated with a higher set continuous flow amplifies environmental sounds, which can adversely affect a developing infant's hearing. ${ }^{17}$ The type of noninvasive interface used has a profound effect on the difference between set and delivered pressures. ${ }^{18}$ Non-occlusive interfaces are associated with a greater variable leak and reduced pressure delivery. When active humidification was used in conjunction with a continuous-flow CPAP gener- ator, condensate present in the expiratory limb of the circuit increased resistance to flow in the circuit and delivered pressures that were higher than set. ${ }^{19}$

The Downs Flow Generator (Vital Signs, Carnegie, Pennsylvania) is an example of a continuous CPAP system which was among the earliest commercially available systems for use. A 50-psi gas source was used to power this device. Variable $\mathrm{F}_{\mathrm{IO}_{2}}$ and flows can be obtained by adjusting the valves which control the amount of gas delivered to the patient through the source-gas and air-entrainment port. Valve 1 controls the amount of air entrained through the entrainment port, while valve 2 controls the amount of flow delivered from the high-powered oxygen gas source (Fig. 2) ${ }^{20-22}$ Pressure within the CPAP system is regulated at the patient mask with a threshold-resistor valve. ${ }^{21}$ These small, relatively portable devices have high gas consumption. The literature reports that, at lower oxygen concentrations, there was a greater flow of gas through the airentrainment port, which created noise levels in excess of $67 \mathrm{dBa}$ when a mask was used as the interface, and in excess of $94 \mathrm{dBa}$ when the helmet interface was used. ${ }^{22}$ The noise levels produced by this device with the aforementioned interfaces exceeded the noise level produced during routine staff activity in an intensive care environment, which is $50-60 \mathrm{dBa} .{ }^{23}$ The noise level produced with the helmet is comparable to the noise levels produced by a functioning food processer. ${ }^{24}$ Excessive noise levels in the ICU environment have been linked to poor quality of sleep, which in turn has adverse consequences on the immune and respiratory status of critically ill patients..$^{25}$

The WhisperFlow (Phillips, Murrysville, Pennsylvania) also uses an oxygen-driven Venturi to entrain air and can produce continuous gas flows $>100 \mathrm{~L} / \mathrm{min}$. Figure 3 


\section{DEVICES FOR CPAP}

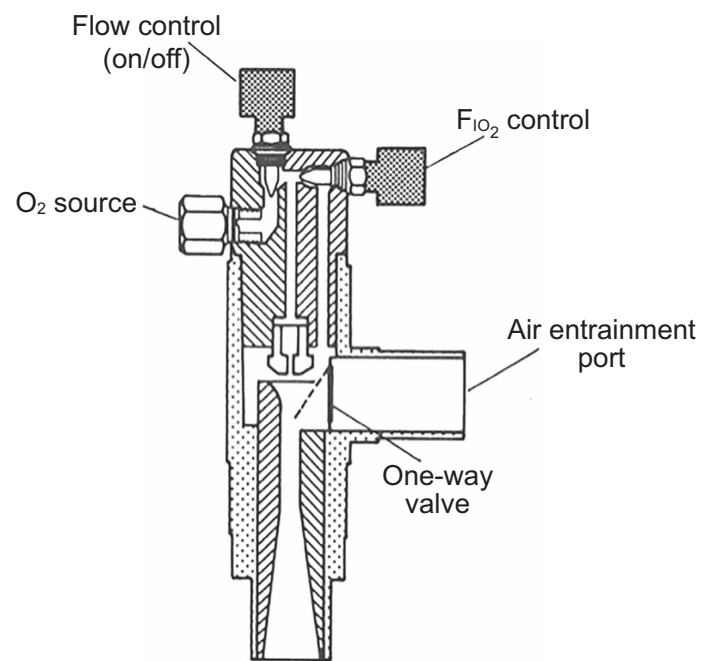

Fig. 2. A schematic of the Downs Flow Generator (Vital Signs, Carnegie, PA) used to provide the continuous flow of the gas to a mask and threshold resistor assembly. From Reference 21, with permission.

illustrates the 2 different available models. The fixed-flow generator delivers flows of approximately $150 \mathrm{~L} / \mathrm{min}$ and oxygen concentrations of $28-33 \%$. The variable-flow generator allows the operator to adjust both the flow of gas and oxygen concentration to the patient and can deliver flows of $10-150 \mathrm{~L} / \mathrm{min}$ and oxygen concentrations of 21-100\%.26 Similar to the Downs Flow Generator, a 50psi gas source is required for operation. Uncalibrated dials adjust valves that control the flow of gas through the CPAP system. ${ }^{27}$ A spring-loaded threshold resistor on the expiratory side of the dual-limb circuit is used to maintain constant pressure in the system. ${ }^{28}$ Dials on this device allow the operator to adjust the flow of gas from the generator to the patient. Because these valves are not calibrated and there is no mechanism to monitor the flow of gas delivered to the patient, there is a risk of adjusting flow to a level that may not be sufficient to meet or exceed inspiratory demands. Because flow and $\mathrm{F}_{\mathrm{IO}_{2}}$ are dependent on the pressure within the system, CPAP levels below the intended or prescribed pressure may be delivered. Laboratory investigations with CPAP devices of the Downs Flow Generator type have reported that air-entrainment decreases as pressure within the system increases (ie, at higher-set CPAP levels). ${ }^{28}$ As a result, the total gas flow to the patient decreases, $\mathrm{F}_{\mathrm{IO}_{2}}$ increases, and the pressure delivered to the patient throughout the respiratory cycle will be lower than the desired set pressure. This has the potential to counter the goals of therapy and adversely affect the patient's oxygenation status and work of breathing. A pressure manometer may be integrated into the system to monitor the delivered pressures and provide feedback on the need to adjust the valve setting. This system provides no audible or visual alarms to alert the clinician when the
CPAP levels drop below the desired set level or when changes in patient condition (eg, an increase in minute ventilation) occur that may require adjustments in the continuous flow.

The Boussignac CPAP device (Vygon, Ecouen, France) is composed of a small cylindrical plastic tube (inner diameter $=1.2 \mathrm{~cm}$ ) containing 4 parallel micro-channels to create a flow-dependent pressure as gas flows through the tube (Fig. 4). ${ }^{29}$ Positive pressure is generated from turbulent gas flow within the hollow cylinder. Unlike the aforementioned gas-conserving CPAP devices, this device does not incorporate an air-entrainment device to supplement flow or a mechanism to adjust $\mathrm{F}_{\mathrm{IO}_{2}}$. However, the distal end of the hollow tube is open, allowing the patient to inhale additional flow from ambient air if needed.

Device performance depends on the oxygen flow setting required to power the device and the amount of entrained air the patient inhales to meet his/her total flow needs. Device evaluations report that the flows generated by the Boussignac CPAP device were much less than those generated by oxygen-conserving air-entrainment CPAP devices. Flow outputs of $<60 \mathrm{~L} / \mathrm{min}$ and a maximum CPAP level of only $9 \mathrm{~cm} \mathrm{H}_{2} \mathrm{O}$ were reached with a flow input of $30 \mathrm{~L} / \mathrm{min} .{ }^{30}$ Access to additional flow from ambient air is available from the open distal end of the hollow tube, should the patient's inspiratory flow needs exceed the flow provided through the device. Because the system is not closed, any additional flow of ambient air dilutes the concentration of oxygen concentration and lowers the delivered airway pressure. ${ }^{30}$ Compared to high and low gasconserving air-entrainment CPAP devices in a simulated patient, greater variations in expected CPAP level were found with the Boussignac CPAP device. ${ }^{30}$ Minute ventilation changes have a profound effect on $\mathrm{F}_{\mathrm{IO}_{2}}$ delivery. In healthy subjects and subjects requiring care in the ICU, Mistraletti et $\mathrm{al}^{31}$ reported a statistically significant decrease in $\mathrm{F}_{\mathrm{IO}_{2}}$ when inspiratory peak flow or minute ventilation (ie, tachypnea or larger tidal volume) increased when a Boussignac device was used to deliver CPAP (Fig. 5). Compared to high and low gas-conserving air-entrainment CPAP devices, greater variations in expected CPAP level were found with the Boussignac CPAP device. ${ }^{31}$ The fluctuations in the CPAP level, occurring when the subjects had an increased inspiratory demand, have the potential to further exacerbate the work of breathing and contribute to respiratory muscle fatigue and increasing respiratory distress. ${ }^{32}$ As flow is increased through the device, a concomitant increase in noise production was noted. Noise levels, measured at a 1-m distance from the functioning device, were noted to be $55 \mathrm{dBA}$ at a flow of $15 \mathrm{~L} / \mathrm{min}$ and $40 \mathrm{dBA}$ at a flow of $5 \mathrm{~L} / \mathrm{min} .{ }^{33}$ The literature reports improvements in $\mathrm{F}_{\mathrm{IO}_{2}}$ delivery, and stability of delivered CPAP pressures were obtained in an experimental design that added a reservoir bag between the mask and 


\section{DEVICES FOR CPAP}

A

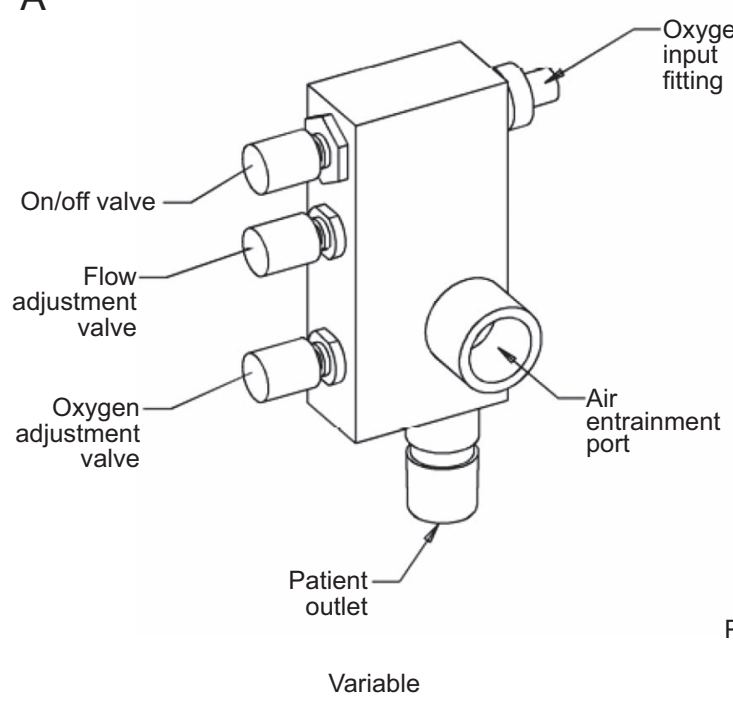

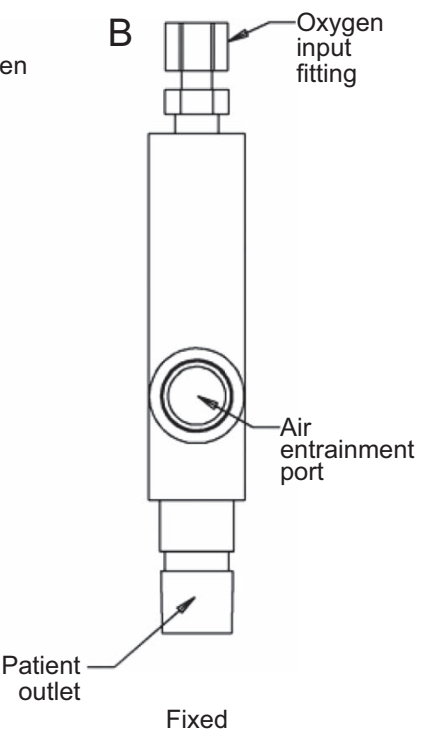

Fig. 3. An illustration of the WhisperFlow CPAP generator (Phillips, Murrysville, PA). A: This model provides fixed outputs for flow and $F_{1 O_{2}}$. $\mathrm{B}$ : This model has control valves that allow the operator to adjust flow and $\mathrm{F}_{\mathrm{IO}_{2}}$ output. From Reference 26 , with permission.

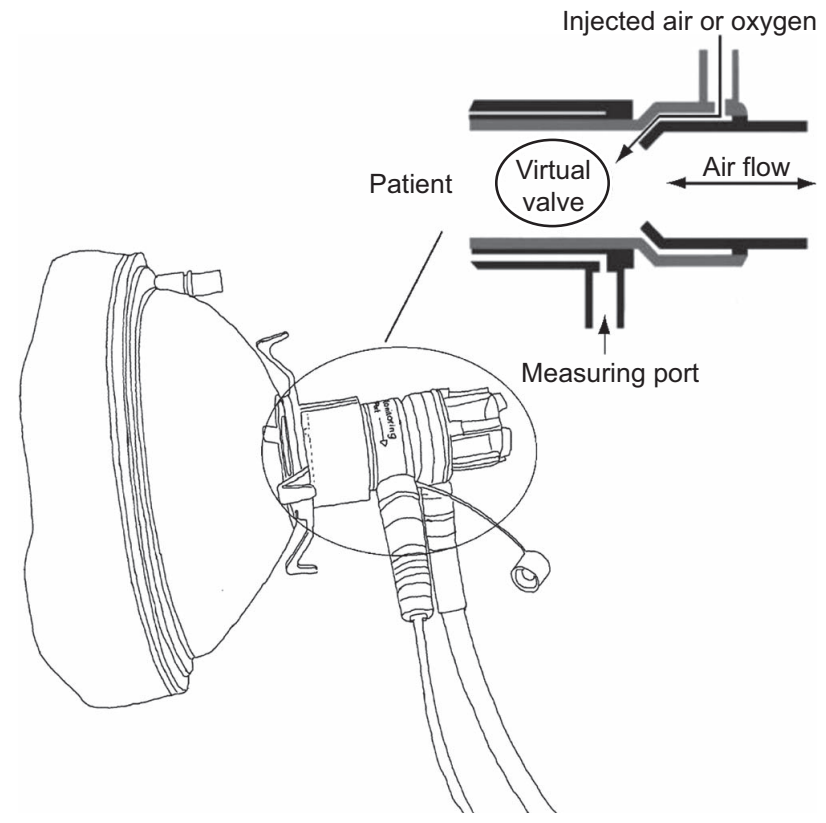

Fig. 4. A schematic illustration of the Boussignac CPAP device (Vygon, Ecouen, France), which is composed of a CPAP mask connected to a small cylindrical plastic tube. Gas from an oxygen source flows through the four parallel micro-channels within the tube independently, creating turbulent gas flow and positive pressure within the hollow cylinder. From Reference 32.

the valve assembly of the Boussignac CPAP device (Fig. 6). ${ }^{34}$ The addition of the reservoir bag allowed $\mathrm{F}_{\mathrm{IO}_{2}}$ to be adjusted independently of CPAP pressure. ${ }^{34}$ When supplemental oxygen flows of $30 \mathrm{~L} / \mathrm{min}$ were used, $\mathrm{F}_{\mathrm{IO}_{2}}$ delivery remained $>0.90$ and minimal variations in CPAP $(7$, 10 , and $13 \mathrm{~cm} \mathrm{H}_{2} \mathrm{O}$ ) levels were found, even when in-

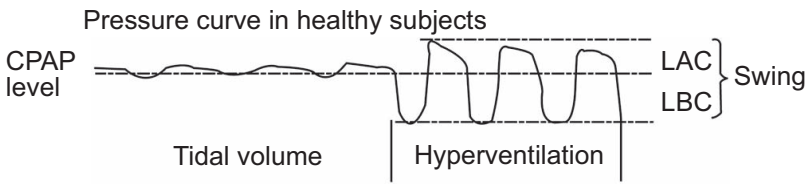

Fig. 5. Pressure and flow tracings in healthy subjects during normal tidal volume breathing and hyperventilation, where inspiratory effort and flow demands are increased demonstrating greater pressure fluctuations, with much lower pressures maintained during the expiratory phase. LAC = level above CPAP due to dynamic hyper-pressurization, $\mathrm{LBC}=$ minimum airway pressure level below CPAP, swing = airway pressure oscillation around the CPAP level. From Reference 31.

spiratory flow increased (up to $60 \mathrm{~L} / \mathrm{min}$ ) in the simulated patient. ${ }^{34}$ This modification provided a more constant CPAP pressure through the respiratory cycle and stable high concentrations of oxygen, which addressed the limitations of this device described in the literature. ${ }^{30,31}$ Table 3 provides a comparison of continuous-flow devices used to deliver mask CPAP.

\section{Portable Demand-Flow CPAP Devices}

Portable demand-flow CPAP devices are commercially available and are used predominantly in the pre-hospital environment. There is a paucity of literature comparing the effectiveness on pre-hospital patient outcomes of demandflow CPAP systems with the continuous-flow CPAP generators or air-entrainment devices. Portable demand-flow CPAP devices require the use of a 50-psi gas source as well as a proprietary circuit. Circuits are single-limb with a built-in (mushroom-type) exhalation valve. There are 


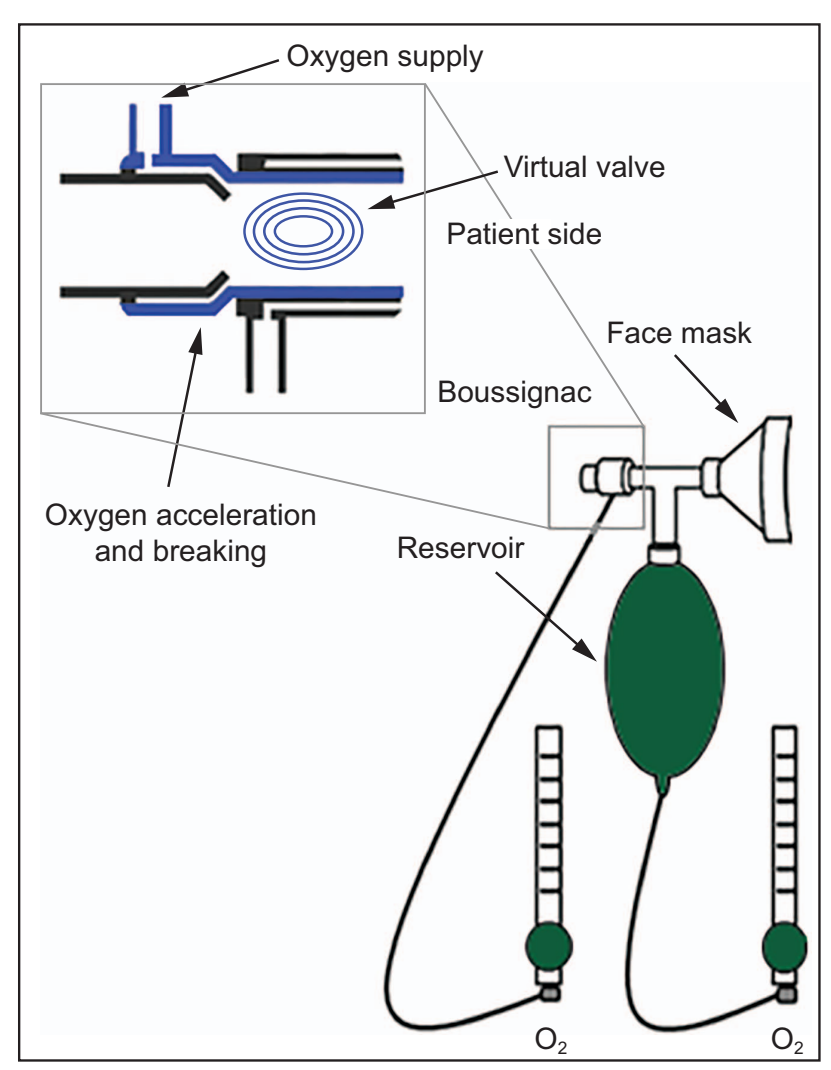

Fig. 6. Example schematic of the experimental design for the Super Boussignac, a modification of the Boussignac CPAP device, incorporating a reservoir bag between the mask (patient interface) and the device's virtual valve assemble. ${ }^{34}$ The reservoir provides a mechanism for additional flow to meet increasing inspiratory flow demands. Adapted from Reference 34.

devices that only allow for noninvasive CPAP and cannot be used with intubated or tracheostomized patients. A mask and head strap bundle provides the patient interface for noninvasive CPAP administration. Some demand-flow CPAP devices require an operational verification to be completed prior to patient use.

A dial on the face of the unit is used to adjust CPAP pressures. Most CPAP pressure-adjustment dials are uncalibrated and require the clinician to observe the needle indicator on the pressure manometer incorporated into the unit to set, verify, and monitor delivered pressures. Depending on the device, demand gas flow may be triggered by either pressure or flow for delivery of flows of $40-100 \mathrm{~L} / \mathrm{min}$ during the inspiratory phase. Typically, devices that are flow-triggered provide a small amount of baseline continuous flow (eg, $10 \mathrm{~L} / \mathrm{min}$ or less) through the circuit. The demand flow will be triggered when the patient requires more than the minimum continuous flow. Research in the early 1980s with rudimentary ICU mechanical ventilators demonstrated a 2-fold increase in work of breathing when healthy volunteers were mechanically ventilated with a demand-flow versus a continuous-flow ventilator. ${ }^{35}$ Device performance can have a profound impact on trigger synchrony and the patient's work of breathing. To optimize patient safety and comfort during CPAP administration, it is important for clinicians to be knowledgeable of the manufacturer specifications for the demand-flow trigger mechanism. Because portable demandflow CPAP devices do not have options to monitor the patent-device interaction, it is important for clinicians to perform a patient assessment to evaluate the patient's work of breathing and response to therapy. Changes in the patient's ventilatory drive due to apnea, dynamic hyperinflation, muscle weakness, or fatigue can contribute to poor patient outcomes if undetected.

Safety features built into portable demand-flow CPAP devices include a manufacturer pre-set pressure-relief valve and anti-asphyxiation ports. The anti-asphyxiation ports are pressure-triggered and can vary from $-2 \mathrm{~cm} \mathrm{H}_{2} \mathrm{O}$ to $-8 \mathrm{~cm} \mathrm{H}_{2} \mathrm{O}$, depending on the unit. However, alarms are not usually available for these types of delivery devices. When used in the pre-hospital and transport settings, this type of CPAP delivery device needs to be secured in the ambulance, mobile ICU, or aircraft to avoid the potential for projectile injury, should sudden changes in the motion of the transport vehicle occur. Portable devices can vary significantly in the pressures they deliver, the amount of flow available to the patient during CPAP delivery, and safety features. Table 4 provides a comparison of 2 commercially available demand-flow CPAP devices cleared for pre-hospital use (ie, MACS CPAP, Airon, Melbourne, Florida; $\mathrm{PortO}_{2}$ Vent, Emergent Respiratory, Carlsbad, California).

\section{Mechanical Ventilator Use for CPAP Delivery}

Mechanical ventilators are the most sophisticated devices used to administer CPAP. Depending on the settings, a critical care ventilator, portable ventilator, or noninvasive ventilator may be used to deliver CPAP along the continuum of care. When CPAP is administered noninvasively through a mechanical ventilator, the amount of work imposed by the device on the patient's work of breathing depends on several factors: the amount of patient effort required for the ventilator to detect inspiratory effort (ie, trigger sensitivity); the length of time it takes the ventilator to start delivering flow once the machine detects patient effort (ie, trigger time delay); and the amount of continuous flow the machine delivers during the respiratory cycle, which affects the patient's resistive work of breathing and has the ability to impose work during the expiratory phase of the respiratory cycle. ${ }^{36,37}$ Historically, when early-generation critical care ventilators were used to deliver CPAP, much effort was needed for the patient to open the ventilator valves to access a flow of blended gas from the circuit. ${ }^{38,39}$ These life-supporting devices have evolved sig- 


\section{DEVICES FOR CPAP}

Table 3. Comparison of Continuous Flow CPAP Generators

\begin{tabular}{|c|c|c|c|}
\hline Device Type & Setting & Advantages & Disadvantages \\
\hline \multirow[t]{2}{*}{ Downs Flow } & \multirow{4}{*}{$\begin{array}{r}\text { Pre-hospital, Emergency } \\
\text { department, Transport }\end{array}$} & Ease of use & No alarms/patient-monitoring features. \\
\hline & & Generates high inspiratory flow & $\begin{array}{l}\text { Pressure delivered is affected by changes in } \\
\text { flow through the system. }\end{array}$ \\
\hline WhisperFlow & & Ease of use & $\mathrm{F}_{\mathrm{IO}_{2}}$ and pressures delivered are flow-dependent. \\
\hline Boussignac & & Ease of use, economical gas consumption & $\begin{array}{l}\text { Boussignac does not deliver flows in excess of } \\
60 \mathrm{~L} / \mathrm{min} \text {. }\end{array}$ \\
\hline
\end{tabular}

nificantly over the past 3 decades. The newer generation of ventilators have complex flow algorithms that allow for more aggressive flow delivery and demand systems designed to lessen the imposed work of breathing. Technical evaluations of mechanical ventilators demonstrate that, depending on the manufacturer, ventilators specified for the same use may respond to the patient-ventilator interaction differently. In an evaluation of 7 new-generation ventilators, Takeuchi et a ${ }^{40}$ reported that although the imposed inspiratory and expiratory work of breathing was less than ventilators manufactured more than 2 decades earlier, ${ }^{41}$ the ventilators evaluated in that laboratory investigation still imposed minor levels of inspiratory and expiratory work load.

Portable ventilators can be used across the continuum of care, from pre-hospital and transport environments to acute and critical care settings. The design and functionality of portable ventilators have greatly improved, facilitating their use for CPAP with sophisticated modes of invasive and noninvasive ventilation. In an evaluation of 8 portable ventilators in a simulated patient, Boussen and colleagues reported a relatively long triggering delay and less responsive trigger sensitivity among pneumatically powered portable ventilators. ${ }^{42}$ The turbine-powered portable ventilators tested were found to be more responsive to weak inspiratory effort and had trigger times of $<100 \mathrm{~ms}$, which was similar to trigger times reported for ventilators used in ICUs. ${ }^{43,44}$ When used in the pre-hospital and inter-facility transport environments, portable ventilators offer an advantage to valved, air-entrainment, continuous-flow or demandflow CPAP delivery systems by providing patient-monitoring systems, alarms, and the ability to provide assisted ventilation when changes in the patient's condition warrant the initiation of mechanical ventilatory support.

Noninvasive ventilators offer an option for CPAP delivery in the ICU as well. Similar to the advances in critical care and portable ventilators, these devices offer an advantage to valved, air-entrainment, continuous-flow or demand-flow CPAP delivery systems by providing capabilities that enhance patient safety and comfort. Typically, noninvasive ventilators use a single-limb circuit to connect the ventilator to the patient interface. Noninvasive ventilators do not have an exhalation valve within the ventilator or the circuit. To facilitate exhalation, an interface with an intentional leak port incorporated into the design is used to administer CPAP or noninvasive ventilation. The flow of gas through the intentional leak depends upon the expiratory pressure setting, the patient's expiratory flow, and the patient's breathing frequency. Therefore, there is a risk of rebreathing carbon dioxide if there is not an adequate continuous flow of gas through the circuit to flush the patient's exhaled volume through the intentional leak. Similar to portable ventilators and ventilators used in the ICU, noninvasive ventilators have anti-asphyxiation valves incorporated into their design.

Noninvasive ventilators have alarm capabilities as well as features to monitor the patient's respiratory status (ie, breathing frequency, tidal volume), quantify and compensate for leaks around the interface, provide assisted ventilation when changes in the patient's condition warrant the initiation of mechanical ventilatory support. ${ }^{45}$ Table 5 provides a list of the features that mechanical ventilators offer for noninvasive CPAP delivery.

Noninvasive and critical care ventilators also have the ability to provide heated humidification with CPAP delivery. Flow through a noninvasive or critical care ventilator during CPAP delivery can cause dryness, reducing patient comfort and tolerance. Inadequate gas conditioning during noninvasive ventilation can impair the anatomy and function of nasal mucosa. ${ }^{46}$ The use of heated humidification increases relative humidity, ${ }^{47}$ attenuates nasal and airway dryness, ${ }^{48}$ and improves patient tolerance of the prescribed therapy. ${ }^{49}$

\section{Device Selection for CPAP Delivery}

Selection of the type of system used to deliver CPAP is dependent upon the care delivery setting. The pre-hospital and transport environments are resource-limited; therefore, the amount and weight of equipment used to stabilize critical patients is important. Equipment for CPAP delivery must be reliable, portable, easy to use, have low gas consumption, and, in the case of portable ventilators, provide battery power sufficient for the duration of the transport. ${ }^{50}$ Devices or systems capable of delivering higher concentrations of oxygen are often of greater importance than precise $\mathrm{F}_{\mathrm{IO}_{2}}$ control because CPAP use in these environments is much shorter in duration than when CPAP is delivered in the ICU. ${ }^{51}$ In a large retrospective study de- 
Table 5. Features of Noninvasive, Critical Care, and Portable CPAP Ventilators

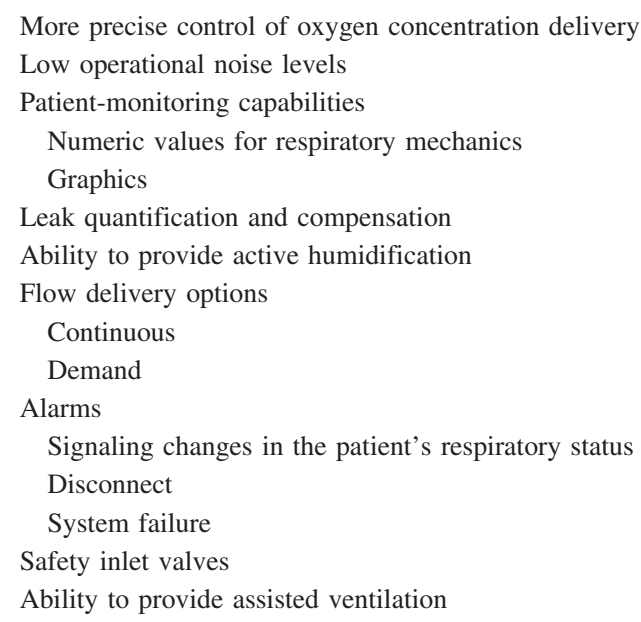

scribing ventilator use by emergency medical service agencies in the United States during 911 emergency calls, ventilators were used in approximately $0.9 \%$ of calls. ${ }^{52} \mathrm{CPAP}$ was the most frequently reported ventilator mode, accounting for $71.6 \%$ of ventilator use. ${ }^{52}$

Conversely, when CPAP is delivered in the intensive care setting, patient safety and comfort are factors that influence device selection. Reliability, however, is one feature that remains important across the continuum of care. Despite robust data supporting the use of CPAP for cardiogenic pulmonary edema and exacerbation of COPD, there are published reports in the prehospital setting that failed to show benefit. For adults with acute cardiogenic pulmonary edema, there are reports in the literature demonstrating similar pre-hospital $\left(0 \%^{53}\right.$ to $\left.8 \%{ }^{29}\right)$ and emergency department $\left(3 \%^{54}\right.$ to $\left.10.5 \%{ }^{55}\right)$ intubations rates when CPAP was provided by EMS providers.

In a pre-post study of pre-hospital CPAP use for respiratory failure due to acute cardiogenic pulmonary edema and exacerbation of COPD, Willmore et $\mathrm{al}^{56}$ found no difference in the need for noninvasive ventilation in the emergency department, length of stay, or mortality for subjects who did or did not receive CPAP in the prehospital setting. The outcome differences noted in the literature may be attributed to study design (ie, inclusion and exclusion criteria, population differences, and subject comorbidities), the type of device used, or the ability of the device or system to reliably deliver the prescribed level of CPAP. It is essential for caregivers to have a thorough understanding of the devices they use to deliver CPAP, including operational characteristics and device limitations. In addition, successful implementation requires methods to enhance patient comfort and maximize the reliability of the prescribed pressure delivery. 


\section{DEVICES FOR CPAP}

\section{Summary}

CPAP has been used along the continuum of care to treat acute and chronic pulmonary manifestations. There are a plethora of systems used to deliver CPAP, ranging from simple devices (eg, valved, air-entrainment, continuous-flow, or demand-flow CPAP delivery systems) to very sophisticated machines (eg, portable, noninvasive, and critical care ventilators). To maximize patient comfort, safety, and effectiveness, it is important for the clinician to have an in-depth understanding of the system used to provide CPAP in their respective setting.

\section{REFERENCES}

1. Barach AL, Martin J, Eckman M. Positive pressure respiration and its application to the treatment of acute pulmonary edema. Ann Intern Med 1938;12(6):754-795.

2. Antonescu-Turcu A, Parthasarathy S. CPAP and bi-level PAP therapy: new and established roles. Respir Care 2010;55(9):1216-1229.

3. Health Quality Ontario. Polysomnography in patients with obstructive sleep apnea: an evidence-based analysis. Ont Health Technol Assess Ser 2006;6(13):1-38.

4. O'Donoghue FJ, Catcheside PG, Jordan AS, Bersten AD, McEvoy RD. Effect of CPAP on intrinsic PEEP, inspiratory effort, and lung volume in severe stable COPD. Thorax 2002;57(6):533-539.

5. Ferrari G, Milan A, Groff P, Pagnozzi F, Mazzone M, Molino P, Aprà $\mathrm{F}$. Continuous positive airway pressure vs. pressure support ventilation in acute cardiogenic pulmonary edema: a randomized trial. J Emerg Med 2010;39(5):676-684.

6. Nouira S, Boukef R, Bouida W, Kerkeni W, Beltaief K, Boubaker H, et al. Non-invasive pressure support ventilation and CPAP in cardiogenic pulmonary edema: a multicenter randomized study in the emergency department. Intensive Care Med 2011;37(2):249-256.

7. Gherini S, Peters RM, Virgilio RW. Mechanical work on the lungs and work of breathing with positive end-expiratory pressure and continuous positive airway pressure. Chest 1979;76(3):251-256.

8. British Thoracic Society Standards of Care Committee. Non-invasive ventilation in acute respiratory failure. Thorax 2002;57(3):192211.

9. Banner MJ, Lamptong S, Boysen PG, Hurd TE, Desautles DA. Flow resistance of expiratory positive-pressure valve systems. Chest 1986; 90(2):212-217.

10. Hillman DR, Finucane KE. Continuous positive airway pressure: a breathing system to minimize respiratory work. Crit Care Med 1985; 13(1):38-43

11. Kacmarek RM, Mang H, Barker N, Cycyk-Chapman MC. Effects of disposable or interchangeable positive end-expiratory pressure valves on work of breathing during the application of continuous positive airway pressure. Crit Care Med 1994;22(8):1219-1226.

12. Lee KS, Dunn MS, Fenwick M, Shennan AT. A comparison of underwater bubble continuous positive airway pressure with ventilator-derived continuous positive airway pressure in premature neonates ready for extubation. Biol Neonate 1998;73(2):69-75.

13. Wu CS, Lee CM, Yuh YS, Hua YM. Influence of changing the diameter of the bubble generator bottle and expiratory limb on bubble CPAP: an in vitro study. Pediatr Neonatol 2012;53(6):359-365.

14. Nowadzky T, Pantoja A, Britton JR. Bubble continuous positive airway pressure: a potentially better practice, reduces the use of mechanical ventilation among very low birth weight infants with respiratory distress syndrome. Pediatrics 2009;123(6):1534-1540.
15. Gupta S, Sinha SK, Tin W, Donn SM. A randomized controlled trial of post-extubation bubble continuous positive airway pressure versus infant flow driver continuous positive airway pressure in preterm infants with respiratory distress syndrome. J Pediatr 2009;154(5): 645-650.

16. Bahman-Bijari B, Malekiyan A, Niknafs P, Baneshi MR. BubbleCPAP vs. ventilatory-CPAP in preterm infants with respiratory distress. Iran J Pediatr 2011;21(2):151-158.

17. Roberts CT, Dawson JA, Alquoka E, Carew PJ, Donath SM, Davis PG, et al. Are high flow nasal cannulae noisier than bubble CPAP for preterm infants? Arch Dis Child Fetal Neonatal Ed 2014;99(4):F291F295.

18. Bailes SA, Firestone KS, Dunn DK, McNinch NL, Brown MF, Volsko TA. Evaluating the effect of flow and interface type on pressures delivered with bubble CPAP in a simulated model. Respir Care 2016;61(3):333-339.

19. Youngquist TM, Richardson CP, Diblasi RM. Effects of condensate in the exhalation limb of neonatal circuits on airway pressure during bubble CPAP. Respir Care 2013;58(11):1840-1846.

20. Fisher GC. The Downs adjustable flow generator. Anaesthesia 1988; 43:766-769.

21. Branson RD, Hess DR, Chatburn RL, editors. Respiratory care equipment. Philadelphia: Lippincott Williams \& Wilkins 1999.

22. Cavaliere F, Conti G, Costa R, Spinazzola G, Proietti R, Sciuto A, et al. Exposure to noise during continuous positive airway pressure: influence of interfaces and delivery systems. Acta Anaesthesiol Scand 2008;52(1):52-56.

23. Simons KS, Park M, Kohlrausch A, van den Boogaard M, Pickkers $\mathrm{P}$, de Bruijn W, de Jager CP. Noise pollution in the ICU: time to look into the mirror. Crit Care 2014;18(4):493.

24. Cavaliere F, Conti G, Costa R, Proietti R, Sciuto A, Masieri S. Noise exposure during noninvasive ventilation with a helmet, a nasal mask, and a facial mask. Intensive Care Med 2004;30(9):1755-1760.

25. Gabor JY, Cooper AB, Crombach SA, Lee B, Kadikar N, Bettger HE, Hanley PJ. Contribution of the intensive care environment to sleep disruption in mechanically ventilated patients and healthy subjects. Am J Respir Crit Care Med 2003;167(5):708-715.

26. WhisperFlow operators manual. Available at: https://shop.medical. philips.com/phstore/catalog/WhisperFlow\%20user\%20man_revD\%20latest.pdf. Accessed December 31, 2018.

27. Fu C, Caruso P, Lucatto JJ, de Paula Schettino GP, de Souza R, Carvalho CR. Comparison of two flow generators with a noninvasive ventilator to deliver continuous positive airway pressure: a test lung study. Intensive Care Med 2005;31(11):1587-1591

28. Glover GW, Fletcher SJ. Assessing the performance of the Whisperflow continuous positive airway pressure generator: a bench study. Br J Anaesth 2009;102(6):875-881.

29. Templier F, Dolveck F, Baer M, Chauvin M, Fletcher D. "Boussignac" continuous positive airway pressure system: practical use in a prehospital medical care unit. Eur J Emerg Med 2003;10(2):87-93.

30. Brusasco C, Corradi F, De Ferrari A, Ball L, Kacmarek RM, Pelosi P. CPAP devices for emergency prehospital use: A bench study. Respir Care 2015;60(12):1777-1785.

31. Mistraletti G, Giacomini M, Sabbatini G, Pinciroli R, Mantovani ES, Umbrello M, et al. Noninvasive CPAP with face mask: comparison among new air-entrainment masks and the Boussignac valve. Respir Care 2013;58(2):305-312.

32. Sehlin M, Törnell SS, Öhberg F, Johansson G, Winsö O. Pneumatic performance of the Boussignac CPAP system in healthy humans. Respir Care 2011;56(6):818-826.

33. Dieperink W, Aarts LP, Rodgers MG, Delwig H, Nijsten MW. Boussignac continuous positive airway pressure for weaning with tracheostomy tubes. Respiration 2008;75(4):427-431. 


\section{DEVICES FOR CPAP}

34. Bellani G, Foti G, Spagnolli E, Castagna L, Patroniti N, Pesenti A. An improved Boussignac device for the delivery of non-invasive CPAP: the SUPER-Boussignac. Intensive Care Med 2009;35(6):1094-1099.

35. Gibney RT, Wilson RS, Pontoppidan H. Comparison of work of breathing on high gas flow and demand valve continuous positive airway pressure systems. Chest 1982;82(6):692-695.

36. Beydon L, Chasse M, Harf A, Lemaire F. Inspiratory work of breathing during spontaneous ventilation using demand valves and continuous flow systems. Am Rev Respir Dis 1988;38(2):300-304.

37. Branson RD, Campbell RS, Davis K, Johnson DJ. Comparison of pressure and flow triggering systems during continuous positive airway pressure. Chest 1994;106(2):540-544.

38. Viale JP, Annat G, Bertrand O, Godard J, Motin J. Additional inspiratory work in intubated patients breathing with continuous positive airway pressure systems. Anesthesiology 1985;63(5):536-539.

39. Katz JA, Kraemer RW, Gjerde GE. Inspiratory work and airway pressure with continuous positive airway pressure delivery systems. Chest 1985;88(4):519-526.

40. Takeuchi M, Williams P, Hess D, Kacmarek RM. Continuous positive airway pressure in new-generation mechanical ventilators: a lung model study. Anesthesiology 2002;96(1):162-172.

41. Hirsh C, Kacmarek RM, Stanek K. Work of breathing during CPAP and PSV improved by the new generation mechanical ventilators: a lung model study. Respir Care 1991;36(8):815-828.

42. Boussen S, Gainnier M, Michelet P. Evaluation of ventilators used during transport of critically ill patients: a bench study. Respir Care 2013;58(11):1911-1922.

43. Zanetta G, Robert D, Guerin C. Evaluation of ventilators used during transport of ICU patients: a bench study. Intensive Care Med 2002; 28(4):443-451.

44. L'Her E, Marjanovic N. Bench-test comparison of 26 emergency and transport ventilators. Crit Care 2014;18(5):506.

45. Scala R, Naldi M. Ventilators for noninvasive ventilation to treat acute respiratory failure. Respir Care 2008;53(8):1054-1080.

46. Wood KE, Flaten AL, Backes WJ. Inspissated secretions: a lifethreatening complication of prolonged noninvasive ventilation. Respir Care 2000;45(5):491-493.
47. Lellouche F, Maggiore SM, Lyazidi A, Deye N, Taillé S, Brochard L. Water content of delivered gases during non-invasive ventilation in healthy subjects. Intensive Care Med 2009;35(6):987-995.

48. Martins De Araújo MT, Vieira SB, Vasquez EC, Fleury B. Heated humidification or face mask to prevent upper airway dryness during continuous positive airway pressure therapy. Chest 2000;117(1):142147.

49. Massie CA, Hart RW, Peralez K, Richards GN. Effects of humidification on nasal symptoms and compliance in sleep apnea patients using continuous positive airway pressure. Chest 1999;116(2):403-408.

50. Schwerin DL, Goldstein S. EMS, Prehospital CPAP Devices. Available at https://www.ncbi.nlm.nih.gov/books/NBK470429. Accessed August 20, 2019.

51. Williams B, Boyle M, Robertson N, Giddings C. When pressure is positive: a literature review of the prehospital use of continuous positive airway pressure. Prehosp Disaster Med 2013;28(1):5260.

52. El Sayed M, Tamim H, Mailhac A, Clay MN. Ventilator use by emergency medical services during 911 calls in the United States. Am J Emerg Med 2018;36(5):763-768.

53. Spijker EE, de Bont M, Bax M, Sandel M. Practical use, effects and complications of prehospital treatment of acute cardiogenic pulmonary edema using the Boussignac CPAP system. Int J Emerg Med 2013;6(1):6-8.

54. Ducros L, Logeart D, Vicaut E, Henry P, Plaisance P, Collet JP, et al. CPAP collaborative study group. CPAP for acute cardiogenic pulmonary edema from out-of-hospital to cardiac intensive care unit: a randomised multicentre study. Intensive Care Med 2011;37(9):1501-1509.

55. Kosowsky JM, Stephanides SL, Branson RD, Sayre MR. Prehospital use of continuous positive airway pressure (CPAP) for presumed pulmonary edema: a preliminary case series. Prehosp Emerg Care 2001;5(2):190-196.

56. Willmore A, Dionne R, Maloney J, Ouston E, Stiell I. Effectiveness and safety of a prehospital program of continuous positive airway pressure (CPAP) in an urban setting. CJEM 2015;17(6):609-616.

\section{Discussion}

Strickland: I'm going back to something Julie [Jackson] mentioned at the end of the presentation by Brady [Scott] because I think it applies here. Not only to our RTs and other clinicians at the bedside in the hospital but also in the prehospital environment with our EMS personnel. Competency, because, obviously, there's a huge variability in the application of these specific devices and whether we know what pressures we're delivering and so forth. How do we make sure that we have the proper application in the prehospital setting, or what can we do to promote that?

Volsko: Thanks Shawna, I think that all comes down to extending the role of the RT outside the hospital to our community partners, which also includes EMS. At our institution, we have the luxury within our transport department of employing an EMS coordinator. The EMS coordinator is the touchpoint or liaison with the EMS community. What we've done in addition to looking at run sheets is to provide a quarterly summary of the run reviews and the review of the patient outcomes (what went well as well as what could have gone better) to our EMS providers. We're also reviewing device interaction with our EMS community and the way it is delivering certain therapeutic modalities out in the field by doing mini boot camps with them on the way the devices work. It's been really great for our therapists and EMS coordinator to work with the cities and townships and the EMS providers. We've had a little bit of difficulty with the private ambulance companies and not as much buy-in to do that type of work.

Scott: I want to make sure I understood you right. Did you say that the analysis of prehospital data is suggestive that CPAP therapy is not effective?

Volsko: There are conflicting reports in the literature, with some studies that reported no difference ${ }^{1,2}$ or CPAP failure, ${ }^{3}$ and I'll go more into this in the paper, but when I looked at the devices used for those studies, I think about device performance. Study outcomes make me question, was it really failure of CPAP therapy or was it device failure that contributed to that patient outcome? 
Scott: I think you're right on target with that. If you think about some of the things we've discussed at this conference, we know that CPAP is effective in the setting of acute cardiogenic pulmonary edema, but, if I' $m$ not mistaken, there has been some benefit shown for CPAP even in hypercapnic respiratory failure. Is that correct, with COPD exacerbation? So, that makes me think that the variable here, this is complex, but it makes me think the variable could be that the devices are not providing the support that they should or seem to be.

Volsko: Most definitely. Even within one class of CPAP devices, this research team demonstrated that all of the devices tested weren't created equal. So, it depends on the device that was used in the particular studies that reported CPAP failure or no benefit; the device used to deliver CPAP could have had a profound impact on patient outcomes.

Hill: CPAP clearly is effective in cardiogenic pulmonary edema and is widely accepted, as recommended by multiple guidelines, including the recent ERS/ATS clinical practice guideline. We also added a sub-recommendation that conditionally suggested its use in the prehospital setting. I worked with the Boston EMS a number of years ago, and they were one of the early adopters of using CPAP in the field. They were using it primarily for cardiogenic pulmonary edema, and I advised them on CPAP use in patients with COPD relevant to Brady's question, and they have been doing that. Obviously, if it's not being applied properly, then it could cause harm. One of the concerns I would have is that, if it's always given with pure $\mathrm{O}_{2}$ in patients with COPD, even though it might have some benefits in counterbalancing auto-PEEP, it could also over-oxygenate patients and that could be an issue. If you slap it on everybody who's short of breath, then you could create some problems.
Volsko: Exactly. And, as you saw, a lot of the devices had very little control over $\mathrm{F}_{\mathrm{IO}_{2}}$ and most of the $\mathrm{F}_{\mathrm{IO}_{2}}$ was controlled by the flow you have through the system. So, if you're not familiar with how the device works, you could really administer harmful levels of $\mathrm{O}_{2}$ to those patients. Again, that's why I thought it was really important to bring up those couple of studies that demonstrated no or a poor effect on patient outcomes when CPAP was administered in the pre-hospital setting since clearly the literature shows the value of CPAP as you pointed out.

* Branson: I've been working in this EMS CPAP realm for 20-25 years. ${ }^{4}$ The devices clearly are an issue. The first thing to remember is it's the positive pressure that matters. The devices you showed, such as the original Downs flow generator, provide a very high flow at a low $\mathrm{F}_{\mathrm{IO}_{2}}$, but it is noisy and there's the perception that it uses a lot of gas. The other demand-valve CPAP systems you showed for EMS often deliver $100 \% \mathrm{O}_{2}$. Our problem has been that both devices require 50 psi. I should preface that half of all EMS calls are for shortness of breath, and the majority are due to congestive heart failure and pulmonary edema, not asthma, not COPD, not respiratory arrest. So CPAP is perfect for that treatment but what happens is you're in the ambulance and you get to the hospital and now you have no way to continue that CPAP therapy, so you either switch to doing some assisted ventilation and put the patient on bag-valve-mask or you put the patient on some $\mathrm{O}_{2}$ delivery device. So the patient has been on CPAP and now you arrive in the emergency department without the positive pressure anymore and the emergency medicine physician says "what are you doing, this guy is drowning in his own se-

* Richard D Branson MSc RRT FAARC, Editor in Chief, RESPIRATORY CARE. cretions?" and then the patient is intubated. I have 2 ideas, one is, wouldn't it be great to do HFNC in the back of the ambulance? But as a transport person, heat, water, electricity, and movement don't always go well together. Outside of that, we need better turbine-driven CPAP systems, and it has to be less expensive. My final comment is there was a paper just published about the use of ventilators during prehospital care. ${ }^{5}$ It's from a data base that's readily available, the National Association of EMS Physicians, and over a $4-y$ period, $<0.5 \%$ of all EMS transports used a ventilator. It's a little more complicated than that because $70 \%$ of those are really just CPAP. So ventilators don't get used a lot in EMS but CPAP really does.

Hill: I would have concerns about treating patents with pulmonary edema with HFNC. I don't know that you'd get enough positive pressure out of it. It hasn't been adequately studied. For cardiogenic pulmonary edema, it's really the increase in intrathoracic pressure that counts.

\section{REFERENCES}

1. Spijker EE, de Bont M, Bax M, Sandel M. Practical use, effects and complications of prehospital treatment of acute cardiogenic pulmonary edema using the Boussignac CPAP system. Int J Emerg Med 2013;6(1):8.

2. Templier F, Dolveck F, Baer M, Chauvin M, Fletcher D. Boussignac continuous positive airway pressure system: practical use in a prehospital medical care unit. Eur J Emerg Med 2003;10(2):87-93.

3. Willmore A, Dionne R, Maloney J, Ouston E, Stiell I. Effectiveness and safety of a prehospital program of continuous positive airway pressure (CPAP) in an urban setting. CJEM 2015;17(6):609-616.

4. Kosowsky JM, Stephanides SL, Branson RD, Sayre MR. Prehospital use of continuous positive airway pressure (CPAP) for presumed pulmonary edema: a preliminary case series. Prehosp Emerg Care 2001;5(2):190-196.

5. El Sayed M, Tamim H, Mailhac A, N Clay $M$. Ventilator use by emergency medical services during 9-1-1 calls in the United States. Am J Emerg Med 2018;36(5):763-768. 